\title{
«UMBRALES» DE LA ANTOLOGÍA: AUTORÍA Y GÉNERO EN LAS POÉTICAS DE ERNESTINA DE CHAMPOURCIN Y JOSEFINA DE LA TORRE ${ }^{1}$
}

\author{
«THRESHOLDS» OF THE ANTHOLOGY: AUTHORSHIP \\ AND GENDER IN THE POETICS BY ERNESTINA \\ DE CHAMPOURCIN AND JOSEFINA DE LA TORRE
}

\author{
Raquel FERNÁNDEZ MENÉNDEZ \\ Universidad de Oviedo \\ fmraquel@uniovi.es
}

\begin{abstract}
Resumen: El objetivo de este artículo es proponer un análisis de las «poéticas» compuestas por escritoras españolas e incluidas en antologías poéticas publicadas en el siglo XX. Estos paratextos, en los que las autoras exponen sus ideas sobre la creación poética, constituyen un fragmento fundamental para la construcción del sentido de la antología en tanto que libro y un documento de gran relevancia a la hora de estudiar los procesos de autorrepresentación llevados a cabo por las poetas. Para ello, se recurre a las recientes investigaciones que se han desarrollado en torno a la figura del autor desde el ámbito francófono de la mano de especialistas como José-Luis Diaz, Dominique Maingueneau o Jérôme Meizoz, y a la teoría literaria feminista que, desde hace décadas, se ha ocupado de las relaciones entre género y autoría. Finalmente, se analizan las poéticas de Ernestina de Champourcin y Josefina de la Torre incluidas en Poesía española. Antología (Los contemporáneos) (1934) de Gerardo Diego.
\end{abstract}

Palabras clave: estudios autoriales, estudios de género, poesía española, literatura española contemporánea, antologías, Ernestina de Champourcin, Josefina de la Torre.

Abstract: The objective of this article is to analyze the poetics composed by Spanish women writers that are included in poetry anthologies in the $20^{\text {th }}$ century. These paratexts, in which the authors describe their ideas about poetic creation, are fundamental for the comprehension of the anthology as a book and they constitute a key document for the self-representation of Spanish women writers. For that purpose, I recur to recent works developed around the question of the author in the francophone

1 Este artículo se enmarca en el Programa Severo Ochoa (referencia PA-17-PF-BP16126) de Ayudas predoctorales para la investigación y la docencia del Gobierno del Principado de Asturias. 
context, with the works of Jose-Luis Diaz, Dominique Maingueneau, Jérôme Meizoz or Ruth Amossy at the forefront, and to the feminist literary theory that during decades has been focused on the relationship between gender and authorship. Finally, I study from this point of view the poetics by Ernestina de Champourcin and Josefina de la Torre included in Poesía española. Antología (Los contemporáneos) (1934) by Gerardo Diego.

Keywords: Authorship, Gender Studies, Spanish Poetry, Spanish Contemporary Literature, Anthologies, Ernestina de Champourcin, Josefina de la Torre. 


\section{$\mathbf{L}$}

\section{a antología y la recuperación de sus «umbrales»}

En los últimos años, las antologías poéticas han recibido destacada atención por parte de la crítica especializada (Ruiz Casanova, 2007; Palenque, 2007; García, 2016; García, 2017; Molina Gil, 2018), cuyas aportaciones han continuado indagando en la importancia que ya en investigaciones previas (Guillén, 2005: 375-378; Pozuelo Yvancos, 2000: 125-127; Romero Tobar, 2006: 57-59) se concedía a estos soportes en la discusión en torno a la disciplina de la Historia literaria y los procesos de formación del canon. Desde esta perspectiva, los criterios de selección que son la base de las antologías han tenido tradicionalmente un enorme impacto en el posterior reconocimiento de ciertos nombres o corrientes en la historia de la literatura; por ello, se repara en las ideas estéticas expuestas por antólogos/as y en la selección de textos que cada volumen incorpora con el fin de conocer las dinámicas que han pautado la supervivencia de determinados textos. Si bien este punto de vista ilumina el estudio de las relaciones entre literatura española y canonicidad que comienzan a ser exploradas a finales de los años noventa (Sullà, 1998), también es cierto que ha alejado del debate el análisis de los paratextos propios de la antología, que no solo condicionan el sentido de los textos que la integran, sino que plantean interesantes retos teóricos. Entre ellos, el título, el prólogo, los poemas seleccionados, las notas biográficas o las poéticas, pero también los retratos de los/las escritores/as y los distintos elementos iconográficos que, en forma de ilustraciones o fotografías, resultan fundamentales para definir la antología en el mapa de las prácticas editoriales contemporáneas.

Con todo, siguiendo las ideas de Gérard Genette sobre el paratexto (Genette, 2001), José Francisco Ruiz Casanova defiende su importancia, por contribuir «en alto grado a perfilar la autoría del antólogo y a construir el libro como tal» (Ruiz Casanova, 2007: 163). En su innovadora investigación, estos elementos se recuperan para proponer un cambio de paradigma en el que la antología no es solamente una reunión de poemas escogidos mediante el empleo de distintos criterios (temáticos, programáticos o históricos) y destinada a la consagración de ciertos nombres, sino un objeto artístico elaborado a través de técnicas similares a las que en las artes plásticas definen al collage (Ruiz Casanova, 2007: 23). En este sentido, como «umbrales», en la terminología de Genette, suponen espacios de paso entre el adentro y el afuera del texto, necesarios para la comprensión y la coherencia del conjunto, que pueden ser leídos como «zonas de transición» (entre el discurso del antólogo/a y el del resto de autores/as) y «de transacción» (entre las declaraciones del antólogo/a y las ideas literarias del resto) (Genette, 2001: 7-8).

A pesar de que, en general, no se han analizado en profundidad estos paratextos, uno de los «umbrales» que ha recibido cierta atención crítica han sido las poéticas que, de manera cada vez más frecuente, se incluyen en las antologías editadas en España a medida que avanza el siglo XX (Ruiz Casanova, 2007: 181) y donde, cada seleccionado/a, expresa, en unas pocas palabras, sus ideas en torno a la poesía, expone sus temas predilectos, menciona sus influencias o se adhiere a determinadas 
corrientes estéticas. Su estudio se ha caracterizado por una falta de consenso entre quienes, dada la inmediatez y el descuido con los que a menudo están redactadas, consideran la dificultad de valorarlas como una fuente de interés filológico (Provencio, 1988: 10), y quienes las han recuperado como un documento fundamental para el conocimiento de determinadas tendencias de peso en la literatura española contemporánea, como la poesía social (García, 2010) o la eclosión de los «Novísimos» en los años setenta (Prieto de Paula, 1996).

Desde un enfoque teórico, aunque tampoco ha existido un acuerdo firme a la hora de clasificarlas y estudiarlas entre los llamados «textos autopoéticos» (Casas, 2000: 210), diversas aportaciones recientes las han recuperado al margen de los tópicos sobre «su imprecisión metalingüística y conceptual, su asistematicidad y su fragmentariedad» (Casas, 2000: 210), dominantes en la historia de la literatura durante décadas. El desarrollo de etiquetas como «autopoéticas» (Casas, 2000), «poéticas particulares» (Teresa Ochoa, 2002: 185) o «poéticas explícitas» (Badia Fumaz, 2018b) pone de manifiesto la utilización de una terminología propia que permite diferenciarlas del resto de reflexiones en torno al hecho literario que aparecen en los textos de ficción y analizarlas desde ópticas tan diversas como la intencionalidad del autor (Casas, 2000), la metapoesía (Scarano, 2017) o las fronteras que establecen con otros géneros como el ensayo (Rubio Montaner, 1990; Badia Fumaz, 2018d: 88) o la autobiografía (Fernández Urtasun, 2000; Badia Fumaz, 2018d: 90-93).

Sin embargo, en estos últimos trabajos, la consideración de los «textos autopoéticos» como un corpus relativamente autónomo (Lucifora, 2015) no permite comprender muchos de los matices que la poética incluida en la antología tiene en su condición de paratexto. Su localización en los márgenes de la obra resulta determinante para la comprensión del sentido, ya que su naturaleza «transicional» y «transaccional» (Genette, 2001: 7-8) la diferencia de las reflexiones teóricas incluidas en ensayos literarios, epistolarios o volúmenes de autobiografías y memorias. El hecho de que sea un agente externo, el antólogo/a, quien ordene su redacción y de que, en algunos casos, incluso dirija los temas tratados en ella a través de preguntas concretas sobre las que el seleccionado/a debe discurrir es determinante para comprender su sentido en el contexto de la antología. El ejemplo de Poesía social (1965), de Leopoldo de Luis, resulta especialmente ilustrativo. En esta selección se recogía bajo el título «Poética» la que había sido la respuesta de los seleccionados/as a la pregunta por la llamada «poesía social» (Luis, 1965), por lo que se agrupaban bajo el rótulo general, los comentarios de cada autor/a sobre un tema concreto, contribuyendo a delimitar, a través del paratexto, la coherencia de la antología en tanto que libro, y orientando la lectura de los poemas hacia el punto de vista de la literatura comprometida.

Desde esta óptica, las poéticas de la antología están estrechamente vinculadas a los objetivos programáticos que la han caracterizado, es decir, al interés por consagrar determinadas corrientes y grupos en el campo literario que define gran parte de las selecciones publicadas a lo largo del siglo XX (Ruiz Casanova, 2007: 134-139). La conexión de las antologías con la preparación de «cánones selectivos» que, a la larga, conformarán un «canon oficial», institucionalizado en las historias de la literatura y en el sistema educativo (Fowler, 1979: 98-99), somete a estos paratextos a un pacto entre 
los procesos de lectura, escritura y relectura del antólogo/a y la exposición de las ideas estéticas del seleccionado/a, que pueden amoldarse o resistirse al programa del conjunto, pero que, en todo caso, no deben ser leídas de forma independiente. Así, la centralidad del yo autorial, que se ha destacado como una de las más importantes características de esta clase de textos (Dulcifora, 2015; Badia Fumaz, 2015: 164), adquiere aquí una especial complejidad. Como espacios de «transición» y «transacción», las poéticas establecen, en palabras de Arturo Casas, un «tupido plexo de líneas de fuerza» que tiene lugar:

1) entre las autopoéticas presentes en una antología dada; 2) entre cada una de ellas y la correspondiente obra poética seleccionada; 3 ) entre los autores; 4) entre estos y el antólogo y, finalmente, 5) entre la antología actual como propuesta alternativa, o como intervención en el campo literario, y la serie textual a la que viene a incorporarse (Casas, 2000: 216).

Es justamente esta cadena paratextual que caracteriza a las antologías, y en la que la poética tiene una especial relevancia por constituir un punto de encuentro entre el antólogo/a y el seleccionado/a, lo que las convierte en un espacio privilegiado para la reflexión en torno a la figura del autor y, como se demostrará, sobre las complejas relaciones entre género y autoría.

\section{Género y «postura» en las poéticas}

En este sentido, no es posible estudiar las poéticas sin tener en cuenta los avances que en los últimos años se han producido desde el análisis del discurso y la sociología de la cultura francófonas en torno a la figura del autor, perspectiva desde la que, aunque de forma parcial, las han leído ya algunos de los artículos citados (Casas, 2000; Scarano, 2017: 141; Badia Fumaz, 2018a; Badia Fumaz, 2018c). Entre otros, los trabajos de José-Luis Diaz (2007), Dominique Maingueneau (2015) o Jérôme Meizoz (2015) recuperan el debate iniciado en 1968 en torno a la autonomía de la escritura con «La muerte del autor» de Roland Barthes (Barthes, 1987), para continuar el camino abierto por Michel Foucault en la búsqueda de aquellos espacios donde, aún como «lugar vacío», el autor «ejerce su función» (Foucault, 2014: 33-34). Como comenzaba a vislumbrarse en el texto de Foucault, la noción de autoría está definida por la intersección entre lo individual y lo colectivo, y determinada por la localización del escritor en el «régimen mediático» (Heinich, 2012), que atraviesa las relaciones de atribución y apropiación de los textos (Pérez Fontdevila y Torras Francés, 2016: 17-18).

De este modo, el desarrollo de conceptos como los de «escritor imaginario»(Diaz, 2007), «imagen de autor» (Amossy, 2014; Maingueneau, 2015) o «postura» (Meizoz), que inciden en la condición de la autoría como una realidad inestable, sometida no solo a los textos y a su periferia, sino también a la proyección pública del escritor y a cómo esta se retoma por los distintos agentes que componen el campo literario, supone un apoyo teórico fundamental para el estudio de las poéticas incluidas en las antologías contemporáneas, donde la voluntad del seleccionado/a de afianzar su consagración está, en gran medida, supeditada a las «líneas de fuerza» (Casas, 2000: 216) que establece con el resto de los elementos del conjunto y con la recepción de la propuesta canónica que está implícita en toda selección. A pesar de la cercanía de estas nociones entre sí, cuyas diferencias han sido 
matizadas por Amossy (2014), Meizoz (2014) o Pérez Fontdevila y Torras Francès (2015), es concretamente el término «postura», propuesto por Jérôme Meizoz, el que resulta especialmente iluminador a la hora de analizar la imagen de sí que el autor/a proyecta en la poética. Si bien la «postura» puede definirse como «la presentación de sí que hace un escritor tanto en la gestión del discurso como en sus conductas públicas» (Meizoz, 2014: 86), lo que aquí resulta fundamental es, por un lado, el énfasis que Meizoz otorga al proceso de negociación del productor del texto con una determinada representación autorial bien asentada en la tradición y rápidamente identificable por todos los miembros del «campo discursivo» (Meizoz, 2015: 5-6) y, por otro, la atención que el investigador presta a los textos autobiográficos y autoficcionales que, como se ha planteado en algunos artículos (Fernández Urtasun, 2000; Badia Fumaz, 2018b), establecen una clara relación con la poética ya que, en ambos, el «pacto autobiográfico» planteado por Philippe Lejeune (1975) permite la asimilación entre autor y el enunciador del texto (Meizoz, 2014: 86-87).

Debido a que la «postura» incluye los «actos enunciativos e institucionales complejos mediante los cuales una voz y una figura adquieren un reconocimiento en el campo literario» (Meizoz, 2015: 4), este término es especialmente eficaz a la hora de dar cuenta de las respuestas de las escritoras en las poéticas, puesto que permite comprenderlas en vínculo con el entramado institucional que determina las representaciones históricas de la autora y del que la antología depende:

En tanto imagen colectiva, esta comienza con el editor justo antes de la publicación, en esa primera formalización del discurso. La seguiremos a lo largo de la periferia del texto, desde el peritexto (presentación del libro, noticia biográfica, foto) al epitexto (entrevistas con el autor, cartas a otros escritores, diario literario). La postura se forja así gracias a la interacción entre el autor, los mediadores y los públicos, anticipando o reaccionando a sus juicios (Meizoz, 2014: 86).

Esta cita revela la importancia de los márgenes del texto para la definición de la «postura». Al recuperar las notas biográficas, las cartas o los retratos del escritor, esta noción resulta especialmente pertinente a la hora de leer la poética desde su condición paratextual. De este modo, en tanto que la poética revela una voluntad expresa de determinar la imagen de la obra que se presenta y de su autor/a, supone un documento fundamental para la «postura» que, sin embargo, ha de ser puesto en relación con el resto de los elementos que definen la presencia del escritor/a en el universo mediático.

Justamente por el diálogo entre la presentación que un autor/a hace de sí y la interpretación por parte de la comunidad crítica y académica que determina su reconocimiento, el estudio de las poéticas incluidas en las antologías encierra, a través de la noción de «postura», una especial complejidad en el caso de las escritoras que, tradicionalmente apartadas de las nóminas programáticas que operan como herramientas de consagración, comienzan a aparecer en estas selecciones a lo largo del siglo XX, al mismo tiempo que la poética se hace cada vez más común en este tipo de libros. Si bien trabajos como los de Hélène Cixous (1995), Joanna Russ (1983) o Christine Planté (1989) ponían de manifiesto las dinámicas responsables de la sistemática exclusión de las mujeres de los espacios que, como las antologías, garantizan el acceso a una cierta notoriedad, solo la reciente aproximación entre la teoría literaria feminista y las investigaciones centradas en el análisis de la figura autorial anteriormente citadas (Pérez Fontdevila y Torràs Francès, 2019) ha contribuido a la comprensión de las 
representaciones históricas de la autora, y, especialmente, ha permitido profundizar en sus estrategias de autorrepresentación en un enclave marcado por el peso de los discursos que niegan su capacidad para la actividad creativa.

Como ha quedado subrayado en numerosos trabajos académicos (Cixous, 1995: 14-15; Pérez Fontdevila, 2019: 27), la misma lógica binaria que ha asentado la radical oposición entre hombres y mujeres en el tejido social a partir de los pares mente/cuerpo y cultura/naturaleza, ha sido igualmente determinante para limitar el acceso de las mujeres a la autoría. Esta estructura bimembre supone su restricción al ámbito de la reproducción biológica (Stanford Friedman, 1987: 52) y, por tanto, la negación de la autonomía y subjetividad que son propias del artista (Pérez Fontdevila y Torras Francés, 2016: 49). Privadas simbólicamente de la originalidad que es indisociable del autor por permitirle «desligarse de su entorno» (Schaeffer, 2016: 248), aquellas escritoras cuya vocación no encuentra acomodo entre las rígidas fronteras impuestas al universo creativo serán consideradas desde la rareza o la excepcionalidad (Russ, 1983: 76-77), lo que, a su vez, explica la «ansiedad de la autoría» que Sandra M. Gilbert y Susan Gubar acuñaron como una de las características fundamentales de la literatura hecha por mujeres (Gilbert y Gubar, 1998: 18-28) y que vertebra gran parte de las poéticas escritas por las poetas españolas en la primera mitad del siglo XX.

Las representaciones históricas de la autoría femenina tendrán importantes consecuencias en el modo en que las escritoras asimilan el repertorio postural que, como subraya Jérôme Meizoz, identifica al autor en el contexto de la comunidad (Meizoz, 2014: 86) y está en la base en los códigos de redacción de la poética. En este sentido, Aina Pérez Fontdevila se pregunta hasta qué punto nociones como la de «postura» prevén «su encarnación en femenino» (Pérez Fontdevila, 2019: 26), ya que si bien es cierto que la comprensión de la autoría como una «figura imaginaria» (Amossy, 2014: 67), definida por el conjunto de prácticas vinculadas con la visibilidad del escritor/a en el «régimen mediático» (Heinich, 2012) y ligada a determinadas «escenografías» (Diaz, 2007) que conviven en un espacio y tiempo determinados, ha permitido desarticular la cadena bimembre anteriormente descrita, sin embargo, por lo general, estos estudios no han asumido una perspectiva de género. Al abordar las poéticas escritas por mujeres, no es posible obviar que su redacción en el contexto de la antología ha estado condicionada por el reconocimiento de su autor/a y, por tanto, la autoridad del firmante depende no solo del prestigio de quien selecciona, sino, además, de las condiciones editoriales y de recepción que la definen como libro. Así, la «postura» incluye las estrategias de las autoras para autorrepresentarse en el marco de la antología y de las posibilidades que las convenciones ideadas previamente para un autor no marcado les otorgan para abrir fisuras en el espacio de las tomas de posición. Desde esta perspectiva, el estudio de las poéticas resulta fundamental para comprender qué mecanismos ligados a la asunción de la autoría se activan cuando la conciencia de excepcionalidad dicta la redacción de un texto ligado al reconocimiento. 


\section{Poesía española. Antología (Contemporáneos) (1934) de Gerardo Diego y las primeras poéticas escritas por mujeres}

Sin perder de vista las aportaciones teóricas en torno a los vínculos entre autoría literaria y género expuestas en el apartado previo, es conveniente proponer ahora un análisis de algunas poéticas escritas por mujeres. Para ello, resulta imprescindible partir de Poesía española. Antología (Contemporáneos) (1934), la reedición del libro que Gerardo Diego había publicado en 1932 como Poesía española. Antología 1915-1931, ya que incluye por primera vez a dos escritoras en su nómina, Ernestina de Champourcin (1905-1999) y Josefina de la Torre (1907-2002). Por otra parte, el antólogo también había sido pionero en la primera edición de 1932 en pedir a los seleccionados unas «notas» que definía como «una declaración de principios poéticos, que de todos he solicitado, y que el lector y yo debemos agradecerles. Lo he creído mucho más interesante que hablar yo por cuenta propia» (Diego, 2007: 92), y que suponen la primera versión del paratexto que sentará las bases para su evolución en las antologías publicadas a lo largo de la centuria.

Aunque en la cita reproducida parece concedérsele una gran importancia a la poética como espacio para la recuperación de las ideas literarias de los poetas escogidos tras la intervención del antólogo, es bien sabido que la mayoría no supo responder a esta petición y que, en consecuencia, o bien envió textos escritos con cierto descuido o bien rechazó explícitamente su preparación (Morelli, 1997: 27; Ruiz Casanova, 2007: 183-187). Las poéticas recogidas por Gerardo Diego tampoco fueron tenidas en cuenta en muchas de las reseñas que recibió la antología en su tiempo (que se limitaron a señalar la inclusión y la exclusión de determinados nombres) (Morelli, 1997: 241-343), ni, salvo en algunas excepciones (Mainer, 1981: 215-218; Prado, 1993: 43-67; Pozuelo Yvancos, 2009: 135), por la crítica especializada que, en los últimos años, ha situado a las distintas reediciones de la antología como una referencia indiscutible en el estudio de las relaciones entre literatura española y canonicidad (Ruiz Casanova, 2007: 183-187). Con todo, a pesar de la inestabilidad que estas primeras poéticas tienen si se comparan con las recogidas en las antologías en las últimas décadas del siglo XX (Provencio, 1988: 25), su recuperación resulta fundamental, no solo por la importancia que, por primera vez, el antólogo otorga a estos paratextos para dar cohesión al conjunto (Morelli, 1997: 27), sino, además, por tratarse del primer enfrentamiento entre las poetas y las convenciones de un texto caracterizado por el reconocimiento previo del emisor y marcado por el carácter transaccional entre las propias ideas literarias y la representación que el seleccionador proyecta con la agrupación, perspectiva desde la que suponen un documento fundamental para el estudio de la «autoimagen» proyectada por las dos incluidas (Plaza Agudo, 2016: 682-683).

En las últimas décadas, a través de diferentes trabajos académicos (Mangini, 2001; Kirkpatrick, 2003; Plaza Agudo, 2016; Alonso Valero, 2016), se ha llevado a cabo una importante labor de recuperación del quehacer literario de las intelectuales de preguerra. Con todo, existen importantes vacíos a la hora de comprender hasta qué punto la incorporación de las «modernas» (Magini, 2001) a la creación cultural plantea, a su vez, nuevos modos de encarnar la identidad autorial que, por desarrollarse en las fisuras de un sistema que rechaza de forma explícita el acceso de las mujeres al 
campo literario, han de considerarse como un reto a las representaciones tradicionales de la figura del autor. Las escritoras que se incorporan al espacio social en los años veinte lo hacen en un clima marcado por un notable incremento en la participación de las mujeres en la esfera pública, bien documentado en diversas investigaciones dedicadas a instituciones como la Residencia de Señoritas y el Lyceum Club Femenino, organismos que abrieron el camino a su profesionalización y crearon una sólida red de contactos entre intelectuales y artistas (Zulueta y Moreno, 1993). Sin embargo, simultáneamente, al final de la década de los años veinte los discursos en torno a la inferioridad biológica de la mujer habían adquirido un amplio alcance (Alonso Valero, 2016: 13).

La prestigiosa Revista de Occidente se situó a la cabeza en la divulgación de los juicios sobre la incapacidad femenina para aquellas tareas vinculadas al intelecto, marco desde el que José Ortega y Gasset planteó la cuestión de la autoría. En el primer número, a través de la lectura de Las fuerzas eternas (1920) de Anna de Noailles, el filósofo defendía la impericia de las mujeres para la escritura de poesía. Su falta de talento residía para Ortega en la carencia de la «innata capacidad para lanzar al universo lo íntimo de nuestra persona» (Ortega, 1923: 36), juicios que se enmarcaban en la tradicional dicotomía entre creación y reproducción que, como se ha señalado, ha servido para apoyar el alejamiento de la mujer de la originalidad y la novedad que han caracterizado históricamente al autor (Schaeffer, 2016: 245). Al incluir la poesía escrita por mujeres dentro de los límites de la «previsibilidad y redundancia» (Schaeffer, 2016: 248), Ortega impide la diferenciación de las escritoras de su entorno como seres singulares y, dada su posición privilegiada en la cultura del primer tercio de siglo, sus palabras resultan determinantes para la pervivencia de este rechazo en el imaginario colectivo y condicionan las estrategias de autorrepresentación asumidas por las escritoras que, en términos de excepcionalidad, son mínimamente reconocidas a lo largo de la década siguiente.

El estrecho vínculo que la Revista de Occidente establece con otros organismos garantes de una cierta «distinción» (Bourdieu, 2015) como la Residencia de Estudiantes o las antologías de Gerardo Diego supone una importante barrera para la normalización de la autoría femenina (Alonso Valero, 2016: 21). A pesar de que Susan Kirkpatrick señala que «la inclusión de mujeres constituye una de las formas en que la vanguardia española puso en práctica la modernidad europea» (Kirkpatrick, 2003: 222), la presencia de Ernestina de Champourcin y Josefina de la Torre en la segunda de las antologías mencionadas no resultó, en absoluto, un fenómeno aceptado en su tiempo. La propia Ernestina de Champourcin se refirió en varias entrevistas a las presiones que pesaron sobre el antólogo para que no fueran incluidas (Ascunce, 1991: 13; Landeira, 2005: 240) y, si bien su presencia estuvo en parte motivada por el interés que el reconocido Juan Ramón Jiménez había mostrado en que la poeta figurara en la reedición del texto (Morelli, 1997: 94-96), llama la atención la ausencia de creadoras tan activas en el contexto intelectual de los años treinta como Concha Méndez (Mainer, 2010: 525; Alonso Valero, 2016: 102).

Una de las características de la nómina de 1934 que resulta fundamental para comprender la relación de estas escritoras con el canon poético de los años treinta es la negativa respuesta en muchas de las reseñas publicadas en los meses siguientes a su aparición. Vicente Salas Viu señalaba en la 
revista Cruz y Raya que este segundo volumen había consistido únicamente «en amontonar en torno a aquella primera antología todo eso que amontona, ese monstruoso postizo. Por esto la nueva antología es infinitamente inferior a la publicada en 1932» (Salas Viu en Morelli, 1997: 342). A pesar de que el musicólogo no rechaza explícitamente la inclusión de Ernestina de Champourcin y Josefina de la Torre, considera que la ampliación en el número de nombres le resta importancia al texto base de 1932. Desde esta perspectiva, al formar parte del «monstruoso añadido» de 1934, la inclusión de las poetas hubiera sido mucho más significativa para la conformación del canon de preguerra de haber participado en el primero de los libros. De forma complementaria, Pedro Salinas anotaba un cambio de naturaleza en la segunda antología que resulta igualmente relevante para comprender la relación marginal de las escritoras con la nómina del 27 consolidada por Gerardo Diego. Para Salinas, la segunda no era una selección «de grupo» como lo había sido su predecesora, sino una de corte «histórico». La reedición no consistía únicamente «en una adición de poetas o poesías de aquellos comprendidos dentro de las fronteras de gusto y tendencia que marcaban los límites de la primera, sino estriba en la ruptura de esos límites y en la anexión de otras zonas poéticas distintas» (Salinas en Morelli, 1997: 336-337). Mientras que el texto de 1932 funciona como «canon selectivo» (Fowler, 1979: 98-99) y convierte a Gerardo Diego en «artífice del grupo generacional» del 27 (Morelli, 1997: 23), por el contrario, la siguiente edición, de acuerdo con los objetivos «históricos» expuestos por Salinas, permitía la entrada a otras voces que, por ser añadidas con posterioridad, permanecerían en los márgenes del exquisito círculo trazado en 1932.

Junto con las representaciones dominantes de la autora en el contexto anteriormente esbozado, las condiciones editoriales que determinan la aparición de la segunda de las antologías contribuirán a definir en gran medida la poética de ambas poetas. Si bien el impacto de la primera selección fue mucho mayor para la delimitación del canon posterior, la inclusión de Ernestina de Champourcin y Josefina de la Torre en la segunda de las compilaciones de Gerardo Diego abre un espacio en el campo que, aun encerrado en los márgenes de la excepcionalidad, motivará la puesta en marcha por las poetas de distintas estrategias para presentar su obra en el universo cultural del primer tercio de siglo. Frente a la negación de las capacidades femeninas para la escritura de poesía, bien ejemplificadas por el artículo de Ortega y Gasset, las dos seleccionadas deberán enfrentarse a la redacción de un texto que asume el reconocimiento previo de su autor, por lo que no se trata únicamente de describir el proceso creativo o de participar con mayor o menor intensidad de las corrientes estéticas dominantes en los años treinta, sino de asumir, a través de las posibilidades de legitimación que ofrece la poética, un rol social tradicionalmente negado a las mujeres.

En 1934, Ernestina de Champourcin había publicado tres libros de poesía: En silencio (1926), Ahora (1928) y La voz en el viento (1931), y mantenía una activa participación en la vida cultural madrileña a través de su vínculo con el Lyceum Club Femenino, que ha quedado registrado en su correspondencia (Champourcin y Conde, 2007) y que refleja una clara voluntad de formar parte de las élites asociadas al grupo del 27. Un claro ejemplo de la resolución de ser reconocida en este contexto se observa en los dos pilares que vertebran su poética: por un lado, la expresión de la «inefabilidad» 
(Prado, 1993: 45) de la poesía, la dificultad de expresar con palabras el proceso creativo que es dominante en la concepción de la escritura de vanguardia, y, por otro, la inserción en la tradición española reciente de la mano de la referencia a Juan Ramón Jiménez. La primera de estas facetas está sintetizada en la carencia de «conceptos» expresada por la escritora:

\footnotetext{
¿Mi concepto de la poesía? Carezco en absoluto de conceptos. La vida borró los pocos de que disponía, y hasta ahora no tuve tiempo ni ganas de fabricarme otros nuevos. Por otra parte cuando todo el mundo define y se define, causa un secreto placer mantenerse desdibujado entre los equívocos linderos de la vaguedad y la vagancia (Diego, 1934: 484-485).
}

Mediante la afirmación del «secreto placer» de «mantenerse desdibujado», Ernestina de Champourcin enmarca su propuesta en la concepción elitista de la literatura defendida por el grupo del 27, para quienes la poesía es algo accesible a unos pocos (Pozuelo Yvancos, 2009: 132). Por otra parte, Javier del Prado señala la «parquedad huidiza [...] capaz, sólo, de formular su admiración por Juan Ramón Jiménez» (Prado, 1993: 44) de la poética de la escritora. Efectivamente, la segunda parte de la poética se centra en la segura afirmación de la influencia de Juan Ramón Jiménez, que, por voluntad propia, había decidido no participar en la segunda edición de la antología de Gerardo Diego (Morelli, 1997: 94-102): «Sin embargo no quiero finalizar estas líneas sin expresar un sentimiento concreto: el que me produce la voluntaria ausencia en esta Antología, de Juan Ramón Jiménez, nuestro gran poeta y maestro» (Diego, 1934: 484-485). Los vínculos de estas intelectuales de vanguardia con los referentes masculinos de prestigio fueron fundamentales para su reconocimiento como autoras en el contexto de la Edad de Plata. En este caso, la mención de Juan Ramón Jiménez refleja la voluntad de cumplir con los requisitos que Jean-Marie Schaeffer considera imprescindibles para el reconocimiento de una manifestación artística en tanto que obra de arte: tanto «su anclaje en una tradición, esto es, su grado de similitud respecto a otras obras, como de su diferenciación en relación a ellas» (Schaeffer, 2016: 250). La localización como paratexto de la antología permite además que «el contexto de recepción de la obra la sitúe primordialmente en relación con otras obras del mismo tipo» (251) y que la apuesta estética y autorial de la poeta esté en cierto modo salvaguardada por la herramienta de distinción que es la antología.

Sin embargo, no es posible finalizar el análisis de la contribución de Ernestina de Champourcin a la antología de Gerardo Diego sin traer a colación la «Antipoética» que la escritora publica como presentación a su libro Huyeron todas las islas (1988), ya que permite vislumbrar la verdadera importancia que este paratexto tuvo para la encarnación de una identidad autorial que no está exenta de las contradicciones que caracterizan el diálogo de la escritura hecha por mujeres con los códigos de asentados en la tradición masculina (Gilbert y Gubar, 1998: 31-32). Situada como preliminar a un poemario de madurez, este texto reitera con firmeza gran parte de las ideas expuestas en 1934 (Bellver, 2001: 445). A pesar de la mayor extensión de esta segunda muestra, fruto no solo de la localización en un libro propio, libre ya de las limitaciones que condicionan la extensión del paratexto en la antología, sino también debido a la literaturización que las poéticas experimentan en las décadas centrales del siglo XX (Badia Fumaz, 2018c), la poeta no modifica en lo sustancial su carta de presentación. En este 
sentido, es significativa la reiterada referencia a Juan Ramón Jiménez como modelo estético: «de repente mi admirado, querido y constante amigo Juan Ramón viene en mi ayuda» (Champourcin, 1988: 10), y la reproducción exacta del fragmento citado de la poética de 1934 al final del texto:

Gerardo Diego en su famosa y discutida Antología del año 34 nos pidió a los que participamos en ella una especie de «poética» y en la mía, muy breve, yo decía: «cuando todo el mundo define y se define, causa un secreto placer mantenerse desdibujado entre los equívocos linderos de la vaguedad y la vagancia» (Champourcin, 1988: 12).

La repetición de las mismas palabras como término de la nueva poética de madurez subraya la voluntad de reafirmarse como autora no solo en el presente, sino, especialmente, en el espacio que la antología de 1934 le había abierto en el canon literario. Sin embargo, existe en el texto de 1988 una mayor conciencia de las tensiones entre género y autoría que resulta fundamental para la asunción de la «postura» en una etapa tardía de su producción:

Pero eso de poética sobre lo que los autores acostumbran a disertar en el umbral de un libro y que los editores suelen exigir, es algo que debe ser muy serio y que yo no acabo de ver muy claro.

Sí recuerdo que cuando yo estudiaba bachillerato había un catedrático de Poética y Retórica al que temíamos, sobre todo, las mujeres, por eso de que una mujer examinándose era una especie de fenómeno... (Champourcin, 1988: 12).

En este fragmento, Ernestina de Champourcin muestra una cierta prudencia a la hora de expresar sus ideas en torno al proceso creativo que surge de la conciencia de género de la que parecía estar exenta la poética de 1934. Ha habido un desplazamiento que reside en la liberación del peso que la antología ejerce como herramienta destinada a la consagración y su difícil relación con la escritura hecha por mujeres. Al estudiar ambos documentos, Catherine G. Bellver (2001: 445) considera que este tímido desinterés por la teoría puede ser interpretado como una estrategia de supervivencia en el espacio dominantemente masculino en el que emerge como poeta. Desde su perspectiva, habría que encontrar en la modestia adoptada cierta «ansiedad de la autoría», a la par que un intento de minimizar cualquier amenaza al orden literario establecido en el que se le había permitido participar. Bellver acierta al destacar que sus modestas contribuciones tratarían de evadir el impacto de su llamativa intrusión en el ámbito de privilegios masculinos y su implícita afirmación de la capacidad de las mujeres para la creación poética (Bellver, 2001: 445). Afirmación y modestia a un tiempo parecen ser, ciertamente, los dos polos a partir de los que se construyen ambas poéticas, pero es necesario tener en cuenta que la «Antipoética» de 1988 volverá a reimprimirse en la edición de las obras completas, Poesía a través del tiempo (Champourcin, 1991), obra que demuestra cómo la poeta se va apropiando progresivamente del paratexto para definir su obra literaria en las distintas etapas de su trayectoria con la voluntad de «distinguirse en el campo literario» (Meizoz, 2015: 167).

Una menor premeditación parece existir en la poética de Josefina de la Torre que, en 1934, había publicado los libros Versos y estampas (1927) y Poemas de la isla (1930). Para la comprensión del lugar ocupado por una escritora como Josefina de la Torre con la antología, es necesario tener en cuenta la ligazón con la cultura popular de su tiempo a través de sus papeles como actriz de teatro, labor que, sin duda, dificulta el estatuto autorial de esta poeta en el contexto esbozado. La aproximación a la 
cultura de masas, que, como se ha repetido en múltiples ocasiones (Morelli, 2000; Gubern, 1999), se convierte en una referencia paratextual recurrente en la poesía de vanguardia, no permitió de la misma manera la afirmación del estatuto de autoras para las mujeres que llevaban a cabo actividades profesionales vinculadas al mundo del espectáculo, ya que, para el pensamiento patriarcal dominante, revela la imposibilidad de escapar de lo «ordinario» (Planté, 2019: 123). En parte, el peculiar vínculo de Josefina de la Torre con las artes determina la prudencia a la hora de componer su poética en dos sencillas líneas: «Está tan unida a tanto misterio, que, por desconocida, nunca me había parado a pensar lo que era. Sólo a sentir que es» (Diego, 1934: 554). La poeta canaria coincide con Ernestina de Champourcin en presentar un texto que trata de amoldarse al tono del conjunto a través de la expresión de la «inefabilidad» (Prado, 1993: 44), reforzando así no solo la coherencia de la antología como libro, sino tratando además de adherirse al grupo generacional. Una y otra ponen de manifiesto la asunción de ciertos rasgos «posturales» asociados a la tradición en la que se insertan, pero las marcas de género serán imborrables de otros espacios cercanos al paratexto, en especial, los del nombre propio y las notas autobiográficas.

Así, es necesario retomar la relación de la «poética» con la «autobiografía» (Fernández Urtasun, 2000) para una mejor comprensión de la primera, ya que las notas biográficas que, bajo el rótulo «Vida», sirven de introducción a los poemas seleccionados en la antología, resultan fundamentales para comprender las tensiones entre género y autoría que están en la base de la redacción de estos textos ligados al prestigio de quien los firma. Si, por una parte, la interdependencia de ambos documentos constata la necesidad de estudiar las poéticas incluidas en las antologías en relación con el resto de «umbrales» (Genette, 2001) que, con frecuencia, se incluyen en este soporte, al mismo tiempo, es necesario tener en cuenta la propensión de las escritoras del primer tercio de siglo a la escritura autobiográfica, a través de la que, como ya ha sido destacado (Nieva de la Paz, 2006; Alfonso García, 2007; Plaza Agudo, 2016: 48-78) parecen encontrar un modo de expresarse que no conlleva las limitaciones del resto de géneros. A través de los datos personales, las autoras también llevan a cabo una representación de sí mismas que está destinada a que se las reconozca en el campo literario, pero la «Vida» parece ofrecerles una mayor flexibilidad para escapar de los códigos impuestos por la poética.

En este sentido, es necesario tener en cuenta el rechazo explícito de Ernestina de Champourcin al vínculo entre su nombre y el término «poetisa»: «no puedo oír mi nombre, acompañado por el horrible calificativo de poetisa, sin sentir vivos deseos de desaparecer, cuando no de agredir al autor de la desdichada frase» (Diego, 1934: 484). Esta etiqueta, que hacía referencia a una poesía imitativa, amorosa, e inferior a la escrita por los hombres, es frecuentemente rechazada por un gran número de escritoras que parecen así resistirse «a la homogeneización y a los estereotipos de género» (Pérez Fontdevila, 2019: 47). En el caso de la poeta vasca existe, como bien observa Roberta Quance, un temor a que la obra no se tome en serio por parte de los medios de difusión, que «sea recibida conforme a ciertas ideas preestablecidas (patriarcales) acerca de la poesía femenina y de lo femenino y, en consecuencia, se piensa, no valorada de una manera adecuada» (Quance, 1997: 185). La nota 
autobiográfica demuestra hasta qué punto los discursos dominantes en torno a género y autoría repercuten en la voluntad de ejercer un cambio en la «postura» a través de los distintos espacios que el campo va abriendo a las mujeres a lo largo del siglo XX. Al contrario de lo que ocurrirá en la «Antipoética» de 1988, donde la poeta sí que expresará el difícil encuentro entre la poética y la autoría femenina, en este fragmento se intenta apartar de su trayectoria todo lo que pueda remitir al espacio de «lo ordinario» (Planté, 2019: 123) en el que históricamente se han encerrado las producciones artísticas de las mujeres. Esta perspectiva permite comprender mejor la búsqueda de un referente masculino de prestigio en la poética, así como la prudencia que caracterizaba a la expresión de las ideas estéticas.

En el caso de Josefina de la Torre la distancia entre la poética y la nota autobiográfica es aún mayor. Lo que más destaca en la imagen proyectada por la autora es el entrecruzamiento de los datos de su trayectoria literaria (los recitales en los que ha participado, la publicación de sus poemas en libros y revistas y, también, el magisterio de su hermano Claudio) y las aficiones (el canto y el teatro, pero también el dibujo, el tenis y la conducción). La "Vida" pone en relación autobiografía y creación y, en este sentido, transgrede los límites que la poética parecía imponer a aquellas propuestas autoriales que escapaban del tono del conjunto. Mientras que la autobiografía proyecta una imagen que se resiste no solo a los tópicos de género (actúa, conduce, nada), sino también a los que han comprendido la autoría como desligada «de su entorno» (Schaeffer, 2016: 248), la poética resulta, por su conexión con el reconocimiento, un espacio en el que la autorrepresentación está especialmente ligada al peso de la estética dominante. Como en el caso de Ernestina de Champourcin, la autobiografía permite expresar con mayor eficacia una identidad autorial que no se corresponde con el rol tradicional del escritor, y, si bien ambas poéticas se amoldaban al conjunto, las notas autobiográficas que las preceden ponen en duda la idea de grupo que había sido proyectada en el texto de 1932 (Pozuelo Yvancos, 2009: 129).

En definitiva, el estudio de las poéticas de Ernestina de Champourcin y Josefina de la Torre para la antología Poesía española. Antología (Los contemporáneos) supone un paso fundamental para el análisis de la interacción entre las representaciones tradicionales de la autora, que han impedido su acceso al reconocimiento en el campo literario, y la autorrepresentación que las escritoras llevaron a cabo con el fin de legitimar su actividad literaria. La teoría literaria feminista, de la mano con las recientes aportaciones desde el marco de los «estudios autoriales» (Pérez Fontdevila y Torrás Francés, 2016), pone de manifiesto la necesidad no solo de incluir nombres femeninos en las nóminas canónicas, sino desarticular los discursos que han pesado sobre su exclusión (Russ, 1983: 119-121; Pérez Fontdevila, 2019: 45). En este caso, la antología se revela como un espacio privilegiado para llevar a cabo estos «usos de la teoría» que invitan a repensar los pilares que han regido la construcción de la historia literaria. 
134 | Tropelías. Revista de Teoría de la Literatura y Literatura Comparada, número extraordinario 5 (2019) Raquel Fernández Menéndez

\section{Referencias bibliográficas}

Alfonso García, M. del C. (2007). «Revelar y revelarse: Los textos autobiográficos de Carmen Conde». En un pozo de lumbre. Estudios sobre Carmen Conde. Coords. Eds. Francisco Javier Díez de Revenga y Mariano de Paco. Murcia: Fundación Caja Murcia, pp. 9-32.

Alonso Valero, E. (2016). Machismo y vanguardia. Escritoras y artistas en la España de preguerra. Madrid: Devenir.

Amossy, R. (2014). «La doble naturaleza de la imagen de autor». La invención del autor. Nuevas aproximaciones al estudio sociológico y discursivo sobre la figura autorial. Ed. Juan Zapata. Medellín: Universidad de Antioquía, 2014, pp. 67-84.

Ascunce, J. Á., ed. (1991). Ernestina de Champourcin, Poesía a través del tiempo (antología). Barcelona: Anthropos.

Badia Fumaz, R. (2018a). «El autor en conflicto en las poéticas explícitas del siglo XX», Dicenda, 36, pp. $45-65$.

— (2018b). «Las poéticas explícitas como género». Rilce, 34 (2), pp. 607-628. - (2018c). «La crisis del autor. Figuración actual del poeta en sus poéticas». Aspectos actuales del hispanismo mundial: Literatura-Cultura-Lengua. Ed. Christoph Strosetzki. Berlín: De Gruyter, pp. 7-19.

(2018d). «Hacia una caracterización de las poéticas explícitas. Elementos comunicativos, funciones y tipologías textuales», Castilla. Estudios de Literatura, 9, pp. 87-113.

(2015). «Las poéticas explícitas de José Ángel Valente y Antonio Colinas: caracterización de un género», Madrygal, 18, pp. 161-170.

Barthes, R. (1987). El susurro del lenguaje. Más allá de la palabra y la escritura. Barcelona: Paidós.

Bellver, C. G. (2001). «Ernestina de Champourcin: A Poet and her Poetics», Hispanic Review, 69, pp. 443-465.

Bourdieu, P. (2015). La distinción. Criterio y bases sociales del gusto. Barcelona: Taurus.

Casas, A. (2000). «La función autopoética y el problema de la productividad histórica». Poesía histórica y (auto)biográfica (1975-1999)». Eds. José Romera Castillo y Francisco Gutiérrez Carbajo. Madrid: Visor, pp. 209-218.

Champourcin, E. de (1991). Poesía a través del tiempo, Barcelona: Anthropos. (1988). Huyeron todas las islas. Madrid: Caballo Griego para la Poesía.

Cixous, H. (1995): La risa de la Medusa. Barcelona: Anthropos.

Diaz, J. L. (2007). L'ecrivain imaginaire. Scénographies auctoriales à l'époque romantique. Paris: Honoré Champion Éditeur.

Diego, G. (2007). Poesía española [Antologías], edición de José Teruel, Madrid: Cátedra. (1934). Poesía española. Antología (Contemporáneos), Madrid: Signo.

Fernández Urtasun, R. (2000). «Autobiografías y poéticas: confluencia de géneros narrativos», Rilce, 16.3, pp. 537-556. 
Foucault, M. (2014). «¿Qué es un autor?». La invención del autor. Nuevas aproximaciones al estudio sociológico y discursivo de la figura autorial. Ed. Juan Zapata. Medellín: Universidad de Antioquia, 2014, pp. 33-48.

Fowler, A. (1979). «Genre and the Literary Canon», New Literary History, 11.1, pp. 97-119.

García, M. Á. (ed.). (2017). El compromiso en el canon. Antologías poéticas españolas del último siglo. Valencia: Tirant lo Blanch. (ed.). (2016). «A la ética por la estética. Canon, compromiso poético y antologías en España (siglos XX-XXI)» [número monográfico], Revista Anthropos, 245.

- (2010). La literatura y sus demonios: leer la poesía social. Madrid: Castalia.

Genette, G. (2001). Umbrales. México D.F.: Siglo XXI Editores.

Gilbert, S. M. y Gubar, S. (1998). La loca del desván. La escritora y la imaginación literaria del siglo XIX. Madrid: Cátedra.

Gubern, R. (1999). Proyector de luna: la generación del 27 y el cine. Barcelona: Anagrama.

Guillén, C. (2005). Entre lo uno y lo diverso. Barcelona: Tusquets.

Heinich, N. (2012). De la visibilitée. Excellence et singularité en régime médiatique. Paris: Gallimard. Kirkpatrick, S. (2003). Mujer, modernismo y vanguardia en España (1898-1931), Madrid: Cátedra.

Landeira, J. (2005). «Entrevista con Ernestina de Champourcin», Ernestina de Champourcin. Vida y literatura, Ferrol: Sociedad Cultural Valle-Inclán, pp. 237-262.

Lejeune, P. (1975). Le pacte autobiographique. Paris: Éditions du Seuil.

Lucifora, M. C. (2015). «Las autopoéticas como máscaras», Recial, 6.7, s/p.

Mainer, J. C. (2010). Historia de la literatura española.6. Modernidad y nacionalismo (1900-1939). Barcelona: Crítica.

(1981). La edad de plata (1902-1939). Ensayo de interpretación de un proceso cultural. Madrid: Cátedra.

Maingueneau, D. (2015). «Escritor e imagen de autor». Tropelías, 24, pp. 17-30.

Mangini, S. (2001). Las modernas de Madrid. Las grandes intelectuales de la vanguardia. Barcelona: Península.

Meizoz, J. (2015). Posturas literarias: puestas en escena modernas del autor. Bogotá: Universidad de los Andes.

(2014). «"Aquello que le hacemos decir al silencio": postura, ethos, imagen de autor». La invención del autor. Nuevas aproximaciones al estudio sociológico y discursivo de la figura autorial. Ed. Juan Zapata. Medellín: Universidad de Antioquia, pp. 85-96.

Molina Gil, R. (2018). «Antologuemos. Tendencias, inercias y derivas en las últimas antologías poéticas en la España contemporánea». Kamchatka, 11, pp. 57-109.

Morelli, G. (ed.) (2000). Ludus. Cine, arte y deporte en la literatura española de vanguardia. Valencia: Pre-Textos.

(1997). Historia y recepción de la antología poética de Gerardo Diego, Valencia: Pretextos. 
Nieva de la Paz, P. (2006). «Voz autobiográfica e identidad profesional en las poetas del 27». Hispania, 89.1, pp. 20-26.

Palenque, M. (coord.). (2007). «Antologías poéticas españolas. Siglos XX-XXI» [Número monográfico], Ínsula, 721-722.

Pérez Fontdevila, A. (2019). «Qué es una autora o qué no es un autor». ¿Qué es una autora? Encrucijadas entre género y autoría. Eds. Aina Pérez Fontdevila y Meri Torras Francès. Barcelona: Icaria, pp. 25-59.

Pérez Fontdevila, A. y Torràs Francés, M. (eds.). (2016). Los papeles del autor/a. Marcos teóricos sobre la autoría literaria. Madrid: Arco Libros.

(2015). «La autoría a debate: textualizaciones del cuerpo-corpus (una introducción teórica)». Tropelías, 24, pp. 1-16.

Planté, C. (2019). «La excepción y lo ordinario». ¿Qué es una autora? Encrucijadas entre género y autoría. Eds. Aina Pérez Fontdevila y Meri Torras Francès. Barcelona: Icaria, 2019. 97-142. (1989). La petite soeur de Balzac. Paris: Éditions du Seuil.

Plaza Agudo, I. (2016). Modelos de identidad en la encrucijada. Imágenes femeninas en la poesía de las escritoras españolas (1900-1936). Málaga: Universidad de Málaga.

Pozuelo Yvancos, J.M. (2009). Poéticas de poetas. Teoría, crítica y poesía. Madrid: Biblioteca Nueva. (2000). «Teoría del canon». Teoría del canon y literatura española. Eds. José María Pozuelo y Rosa María Aradra Sánchez. Madrid: Cátedra, pp. 15-142.

Prado, J. del. (1993). Teoría y práctica de la función poética. Madrid: Cátedra.

Prieto de Paula, Á. L. (1996). Musa del 68. Claves de una generación poética, Madrid: Hiperión.

Provencio, P. (1988). Poéticas españolas contemporáneas. La generación del 50. Madrid: Hiperión.

Quance, R. (1998). «Hago versos, señores...». Breve historia feminista de la literatura española (en lengua castellana). V. La literatura escrita por mujer (del siglo XIX a la actualidad). Coord. Iris M. Zavala. Barcelona: Anthropos, pp. 185-210.

Ruiz Casanova, J. F. (2007). Anthologos: Poética de la antología poética. Madrid: Cátedra.

Russ, J. (1983). How to Suppress Women's Writing. Austin: University of Texas Press.

Romero Tobar, L. (2006). La literatura en su historia. Madrid: Arco Libros.

Rubio Montaner, P. (1990). «Sobre la necesaria integración de las poéticas de autor en la teoría de la literatura». Castilla. Estudios de literatura, 15, pp. 183-197.

Scarano, L. (2017). «Escribo que escribo: de la metapoesía a las autopoéticas», Tropelías, 2, pp. 133 152.

Schaeffer, J. M. (2016). «Originalidad y expresión de sí. Elementos para una genealogía de la figura moderna del artista», Los papeles del autor/a. Marcos teóricos sobre la autoría literaria. Eds. Aina Pérez Fontdevila y Meri Torras Francés. Madrid: Arco Libros, pp. 243-278.

Sullà, E. (ed.) (1998). El canon literario. Madrid: Arco Libros.

Stanford Friedman, S. (1987). «Creativity and the Childbirth Metaphor: Gender Difference in Literary Discourse». Feminist Studies 13.1, pp. 49-82. 
Teresa Ochoa, A. de (2002). «Poéticas particulares y universalistas». Anuario de Letras Modernas, 10, pp. 183-192.

Zulueta, C. de y Moreno, A. (1993). Ni convento ni college. La Residencia de Señoritas. Madrid: Residencia de Estudiantes. 